\title{
Glycogen storage disease type 0 due to a novel frameshift mutation in glycogen synthase 2 (GYS2) gene in a child presenting with fasting hypoglycemia and postprandial hyperglycemia
}

\author{
Bülent Hacıhamdioğlu¹, Gamze Özgürhan², Bahar Çaran², Evrim Meydan-Aksanlı², \\ Ece Keskin ${ }^{3}$ \\ Departments of ${ }^{1}$ Pediatric Endocrinology, ${ }^{2}$ Pediatrics and ${ }^{3}$ Medical Genetics, University of Health Sciences, Suleymaniye \\ Women Maternity and Child Diseases Training and Research Hospital, Istanbul, Turkey. E-mail: hacihamdi@yahoo.com.tr \\ Received: 3rd May 2017, Revised: 26th July 2017, 7th September 2017, 21st September 2017, \\ Accepted: 23rd September 2017
}

SUMMARY: Hacıhamdioğlu B, Özgürhan G, Çaran B, Meydan-Aksanlı E, Keskin E. Glycogen storage disease type 0 due to a novel frameshift mutation in glycogen synthase 2 (GYS2) gene in a child presenting with fasting hypoglycemia and postprandial hyperglycemia. Turk J Pediatr 2018; 60: 581-583.

Glycogen storage disease type 0 (GSD0) has been considered a rare disorder, it is characterized with ketotic hypoglycemia after prolonged fasting and postprandial hyperglycemia. Herein, we report a novel mutation in the glycogen synthase 2 gene in a Turkish child, as well as her clinical characteristics and 12-month follow-up. We evaluated a 5-year-old girl for asymptomatic fasting ketotic hypoglycemia with postprandial hyperglycemia diagnosed with glycogen storage disease type 0 . We identified a novel frameshift mutation, c.1081delA (p.Thr361Glnfs*2) in exon 8 on glycogen synthase 2 gene. Children with GSD0 may have a mild phenotype and GSD0 may be underdiagnosed due to subclinical or asymptomatic hypoglycemia. The diagnosis of GSD0 should be considered in a child with ketotic fasting hypoglycemia with postprandial hyperglycemia but without hepatomegaly.

Key words: ketotic hypoglycemia, glycogen storage disease type 0, glycogen synthase 2 gene.

Low blood glucose accompanied by ketosis is the most common type of hypoglycemia in children and may be caused by rare metabolic diseases. ${ }^{1}$ Ketotic hypoglycemia is a major clinical feature of some types of glycogen storage diseases such as types $0, \mathrm{VI}$, and IX. ${ }^{1}$ Glycogen storage disease type 0 (GSD0) is characterized with deficiency of hepatic glycogen synthase encoded by the glycogen synthase 2 (GYS2) gene. The major clinical finding is fasting ketotic hypoglycemia with postprandial hyperglycemia and hyperlactatemia, but without hepatomegaly. ${ }^{1,2}$

Glycogen synthase normally catalyzes the formation of $\alpha$-1,4-linkages, which elongate chains of glucose molecules to form glycogen. In GSD0, glycogen synthesis in the liver is impaired, which renders the patient prone to develop ketotic hypoglycemia and low lactatemia after fasting. After the ingestion of a carbohydratecontaining meal, hyperglycemia is common because glycogen cannot be synthesized. Excess glucose is converted anaerobically to lactate and can cause hyperlactatemia.1,2

Herein, we report a novel mutation in the GYS2 gene in a child, as well as her clinical characteristics and 12-month follow-up.

\section{Case Report}

A 5-year-old girl was referred to the department of pediatric endocrinology with the complaint of short stature. During routine investigation of short stature, fasting blood glucose was 
Table I. Results of Critical Samples at the Time of Hypoglycemia.

\begin{tabular}{lc}
\hline Glucose & $43 \mathrm{mg} / \mathrm{dL}$ \\
\hline $\begin{array}{l}\text { Beta } \\
\text { hydroxybutyrate }\end{array}$ & $5.1 \mathrm{mmol} / \mathrm{L}$ \\
Lactate $(0.7-2.0 \mathrm{mmol} / \mathrm{L})$ & $1.5 \mathrm{mmol} / \mathrm{L}$ \\
Insulin & $<2 \mathrm{IU} / \mathrm{L}$ \\
Cortisol & $24 \mathrm{mcg} / \mathrm{dl}$ \\
Growth hormone & $11 \mathrm{ng} / \mathrm{ml}$ \\
\hline
\end{tabular}

detected at $34 \mathrm{mg} / \mathrm{dl}$ with $3(+)$ ketonuria without clinical symptoms. She was born from consanguineous parents at full-term without complications weighing 3,200 g with normal psychomotor development. Her physical examination was normal. Her height standard deviation score (SDS) was $-2.5(97.5 \mathrm{~cm})$ and relative body weight was $85 \%(12.9 \mathrm{~kg})$. Her mid-parental height was $151.5 \mathrm{~cm}$ (-1.97 SDS).

The patient's glucose profile during hospitalization revealed frequent fasting hypoglycemia with postprandial hyperglycemia $(220 \mathrm{mg} / \mathrm{dl})$ and hyperlactatemia $(5 \mathrm{mmol} / \mathrm{L})$. Her lipid profile was normal. A critical sample was obtained at the time of hypoglycemia (Table I). We observed a rapid glycemic response to glucagon administration at the time of fasting hypoglycemia (from 40 to $70 \mathrm{mg}$ / dl). Glycohemoglobin (HbA1c) level was measured and an oral glucose tolerance test (OGTT) was performed because of postprandial hyperglycemia (Table II).

GYS 2 gene analysis showed that a novel frameshift mutation c.1081delA (p.Thr361Glnfs*2) leading to a premature termination codon was identified in exon 8 (Fig. 1). Genetic analysis of the parents demonstrated that both were carriers of the same mutation. Her parents did not have hypoglycemia based on the fasting test, but OGTT revealed that her father was classified as glucose intolerant (Table II). Her parents were non-obese and did not have any other risk factor for glucose

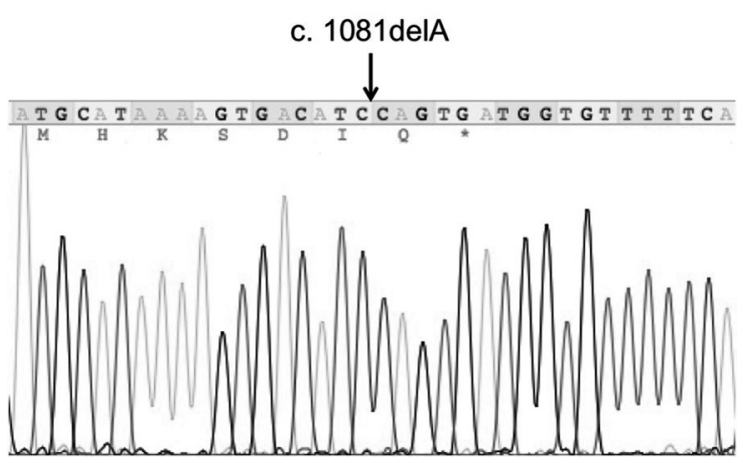

Fig. 1. Homozygous molecular variant c.1081delA (p.Thr361Gln) in the GYS2 gene.

intolerance.

Her initial dietary prescription consisted of three meals and three to four snacks (last one at bedtime) and avoidance of fasting for longer than $8 \mathrm{~h}$ (we determined this time during the follow-up in the hospital). Uncooked cornstarch (bedtime, $1 \mathrm{~g} / \mathrm{kg}$ ) was recommended. In addition, simple carbohydrates were limited. Morning hypoglycemia ( $<50 \mathrm{mg} / \mathrm{dl}$ ) and exaggerated postprandial hyperglycemia (> 180 $\mathrm{mg} / \mathrm{dl})$ resolved with this regimen. She was followed regularly for one year, and her last height is $104.5 \mathrm{~cm}(-2.0 \mathrm{SDS})$ and weight is $15.4 \mathrm{~kg}$. Her growth rate was $7 \mathrm{~cm}$ in 12 months.

Written consent of parents has been obtained.

\section{Discussion}

In this report, we describe a child who was diagnosed as GSD0 with a novel mutation in the GYS2 gene. GSD0 is a very rare disease ${ }^{1-8}$ that presents with a wide phenotypic spectrum, including seizures, fasting ketotic hypoglycemia, hyperglycemia, glucosuria, short stature, and failure to thrive. ${ }^{2,5}$ Our patient presented with short stature, but there were no specific signs of hypoglycemia.

Although short stature is common in inappropriately managed children with GSD, it is rare as a presenting complaint. ${ }^{2}$ Previously, it

Table II. Results Glycohemoglobin (HBbA1c) and Glucose Response During Oral Glucose Tolerance Test.

\begin{tabular}{lccccc}
\hline & HbA1c & Basal glucose & 30 min glucose & 60 min glucose 120 min glucose \\
\hline Patient & $4.8 \%$ & 74 & 200 & 126 & 154 \\
Mother & $5.2 \%$ & 85 & - & 100 & 113 \\
Father & $6.1 \%$ & 94 & - & 148 & 162 \\
\hline
\end{tabular}

*Glucose levels were given in $\mathrm{mg} / \mathrm{dl}$. 
was shown that short stature can be improved by preventing hypoglycemia, lactic acidosis, and ketosis. ${ }^{2,9}$

In our patient, we observed a normal glycemic response to glucagon administration at the time of fasting hypoglycemia. This observation was also reported previously. ${ }^{8}$ We presume that glycogen stores were not completely depleted despite the presence of hypoglycemia, and pharmacological amount of glucagon were able to stimulate their breakdown. ${ }^{8}$ This would be a reasonable explanation for positive glycemic response to glucagon administration which is unlikely in GSD.

Treatment of liver glycogen synthase deficiency consists of frequent protein-rich meals and avoidance of prolonged fasting. Uncooked cornstarch acts as a "slow release" form of glucose and may prevent morning hypoglycemia. Low glycemic index carbohydrates should be preferred to avoid hyperlactatemia and hyperglycemia. It is also known that tolerance to fasting improves with age. ${ }^{2,8}$ We observed the usefulness of this treatment approach in our patient.

To date, 20 different mutations have been documented in the GYS2 gene. ${ }^{1-7}$ A novel homozygous molecular variant c.1081delA (p.Thr361Gln) in the GYS2 gene was identified in our patient. This frameshift mutation leads to a premature stop codon in exon 8. MutationTaster software analysis revealed that this mutation may be associated with the disease.

GYS2 is an important gene for glucose homeostasis. In the present report, the father was a carrier of the mutation and did not develop fasting hypoglycemia. However, he was diagnosed as prediabetic according to the HbA1c and OGTT. This was reported by Soggia AP et $a l .{ }^{6}$. A previous linkage study did not identify this as a major gene contributing to type 2 diabetes susceptibility, but it may be associated with impaired glucose tolerance. ${ }^{8}$ Thus, further studies on heterozygote GYS2 mutation carriers are required.
GSD0 has been considered a rare autosomal recessive disease, but it may be more common where consanguineous marriage is prevalent. Children with GSD0 may have a mild phenotype and GSD0 may be underdiagnosed due to subclinical or asymptomatic hypoglycemia. Appropriate dietary intervention is sufficient for the management of this rare disease. Overall, the diagnosis of GSD0 should be considered in a child with ketotic fasting hypoglycemia with postprandial hyperglycemia but without hepatomegaly.

\section{REFERENCES}

1. Brown LM, Corrado MM, van der Ende RM, et al Evaluation of glycogen storage disease as a cause of ketotic hypoglycemia in children. J Inherit Metab Dis 2015; 38: 489-493.

2. Weinstein DA, Correia CE, Saunders AC, Wolfsdorf JI Hepatic glycogen synthase deficiency: An infrequently recognized cause of ketotic hypoglycemia. Mol Genet Metab 2006; 87: 284-288.

3. Orho M, Bosshard NU, Buist NR, et al. Mutations in the liver glycogen synthase gene in children with hypoglycemia due to glycogen storage disease type 0 . J Clin Invest 1998; 102: 507-515.

4. Szymańska E, Rokicki D, Wątrobinska U, et al. Pediatric patient with hyperketotic hypoglycemia diagnosed with glycogen synthase deficiency due to the novel homozygous mutation in GYS2. Mol Genet Metab Rep 2015; 4: 83-86.

5. Spiegel R, Mahamid J, Orho-Melander M, Miron D, Horovitz Y. The variable clinical phenotype of liver glycogen synthase deficiency. J Pediatr Endocrinol Metab 2007; 20: 1339-1342.

6. Soggia AP, Correa-Giannella ML, Fortes MA, Luna AM, Pereira MA. A novel mutation in the glycogen synthase 2 gene in a child with glycogen storage disease type 0. BMC Med Genet 2010; 11: 3.

7. Nessa A, Kumaran A, Kirk R, Dalton A, Ismail D, Hussain K. Mutational analysis of the GYS2 gene in patients diagnosed with ketotic hypoglycaemia. J Pediatr Endocrinol Metab 2012; 25: 963-967.

8. Laberge AM, Mitchell GA, van de Werve G, Lambert $M$. Long-term follow-up of a new case of liver glycogen synthase deficiency. Am J Med Genet A 2003; 120A: 19-22.

9. Mahtani MM, Widén E, Lehto $M$, et al. Mapping of a gene for type 2 diabetes associated with an insulin secretion defect by a genome scan in Finnish families. Nat Genet 1996; 14: 90-94. 